\title{
ПРИМЕНЕНИЕ МЕТОДА ОДНОВРЕМЕННОЙ РАЗДЕЛЬНОЙ ЭКСПЛУАТАЦИИ ДЛЯ КОНТРОЛЯ И РЕГУЛИРОВАНИЯ ПРОЦЕССА РАЗРАБОТКИ
}

\section{Деряев Аннагулы Реджепович}

к.т.н, научный сотрудник Научно-исследовательский институт природного газа ГК «Туркменгаз»

\begin{abstract}
Аннотация: Одновременная разработка нескольких пластов одним объектом возможна только при одинаковых физико-химических свойствах нефтей в объединяемых пластах, если приток нефти и газа достаточен из каждого пласта при допустимом забойном давлении в скважине, при близких значениях пластового давления в объединяемых пластах, исключающих перетоки нефти между пластами, и близких значениях обводненности пластов.

Ключевые слова: зона нагнетания, интенсификация, добыча, конечная нефтеотдача, обводненность, пластовый флюид, фонд скважин.

\section{APPLICATION OF THE METHOD OF SIMULTANEOUS SEPARATE OPERATION TO CONTROL AND REGULATE THE DEVELOPMENT PROCESS}

\section{Deryayev Annaguly Rejepovich}

\begin{abstract}
Simultaneous development of several formations by one object is possible only with the same physical and chemical properties of oils in the combined formations, if the inflow of oil and gas is sufficient from each formation at an acceptable downhole pressure in the well, with close values of reservoir pressure in the combined formations, excluding oil flows between the layers, and close values of reservoir waterlogging.
\end{abstract}

Key words: injection zone, intensification, production, final oil recovery, waterlogging, reservoir fluid, well stock.

Мировая практика добычи нефти и газа на многопластовых месторождениях показывает, что круг технологических задач, решаемых 
посредством использования одновременной раздельной эксплуатации, весьма обширен и разнообразен. Например, имеется целый ряд задач, касающихся непосредственно проблем контроля и регулирования добычи нефти из многопластового объекта посредством воздействия оборудования ОРЭ на отдельные пласты как в зоне отбора, так и в зоне нагнетания.

Наличие большого количества технологических задач вызывает определенные трудности при оценке экономической эффективности метода одновременной раздельной эксплуатации, т.к. для каждого отдельного случая необходимо было бы иметь определенный метод оценки экономической эффективности. Поэтому систематизация и обобщение задач в группы способствуют разработке ограниченного числа способов определения экономической эффективности методом ОРЭ.

В зависимости от характера основных показателей, определяющих экономическую эффективность и технико-экономическую целесообразность перевода скважин на одновременную раздельную эксплуатацию пластов, цели и задачи применения метода ОРЭ можно подразделить на три основные группы:

1) контроль и регулирование процесса разработки многопластового объекта с целью интенсификации текущей добычи и получения максимальной конечной нефтеотдачи;

2) приобщение новых продуктивных объектов к разработке в эксплуатационных и нагнетательных скважинах с целью получения дополнительной добычи нефти;

3) применение одновременной раздельной эксплуатации с целью решения технологических задач по добыче нефти и газа.

Для каждой из этих трех групп в руководстве даны методы определения технико-экономической эффективности одновременной раздельной эксплуатации.

К первой группе технологических задач можно отнести применение одновременной раздельной эксплуатации с целью:

a) обеспечения оптимального режима работы каждого из пластов, разрабатываемых совместно (создание условий самостоятельной сетки скважин на каждый пласт);

б) регулирования разработки объекта по пластам, имеющим различные коллекторские свойства (равномерная выработка, интенсификация отбора, 


\section{КОНСОЛИДАЦИЯ ИНТЕЛЛЕКТУАЛЬНЫХ РЕСУРСОВ КАК ФАКТОР РАЗВИТИЯ СОВРЕМЕННЫХ ИССЛЕДОВАНИЙ}

ограничение водопритока по одному из пластов, продление сроков фонтанной эксплуатации скважин, раздельный сбор чистой и обводненной нефти);

Применение одновременной раздельной эксплуатации для решения задач первой группы позволяет получить следующие результаты.

Существенное повышение эффективности разработки многопластового месторождения за счет укрупнения эксплуатационных объектов (снижение капиталоемкости, металлоемкости, себестоимости нефти, выигрыш от фактора времени), по сравнению с системой разработки с самостоятельными сетками скважин на каждый пласт.

Достижение запроектированной нефтеотдачи пластов путем обеспечения возможности регулирования процесса выработки запасов по пластам (создание дифференцированных перепадов давления) по сравнению с совместной разработкой пластов при той же плотности сетки скважин.

Увеличение плотности сетки размещения эксплуатационных и нагнетательных скважин при том же или меньшем количестве скважин, что и при раздельной эксплуатации каждого пласта самостоятельными сетками скважин и как следствие, увеличение текущей добычи нефти и конечной нефтеотдачи прерывистых линзовидных коллекторов.

В качестве примера можно привести результаты оценки влияния неоднородности пластов на технико-экономическую целесообразность применения ОРЭ, выполненных на примерах гипотетических многопластовых месторождений, параметры которых были приняты аналогичными параметрам горизонтов месторождений Казахстана:

a) нефтеотдача за 80-летний период разработки при одновременной раздельной эксплуатации пластов с учетом условий регулирования давления выше на 11-16\%, чем при совместной эксплуатации этих же пластов, что равносильно получению дополнительной добычи нефти в количестве 80-40 млн.тонн;

б) сроки разработки неоднородных пластов при ОРЭ с дифференцированными перепадами давления по пластам (условия регулирования) сокращаются в 1,3-1,4 раза по сравнению с совместной эксплуатацией при снижении себестоимости одной тонны нефти на 14-16\%.

Эти данные свидетельствуют о том, что целесообразность решения большинства задач первой группы должна быть установлена еще на стадии проектирования разработки многопластового месторождения.

Эффективность применения ОРЭ при этом выявляется из сравнения технико-экономических показателей разработки месторождения с ОРЭ с 


\section{КОНСОЛИДАЦИЯ ИНТЕЛЛЕКТУАЛЬНЫХ РЕСУРСОВ КАК ФАКТОР РАЗВИТИЯ СОВРЕМЕННЫХ ИССЛЕДОВАНИЙ}

показателями того же месторождения, но без применения одновременной раздельной эксплуатации (соответственно при самостоятельных сетках скважин на каждый пласт, уплотнении сеток скважин дополнительных бурением, совместной разработке пластов при общем забойном давлении скважин, с преждевременным обводнением и переходов скважин на механизированную добычу и неравномерной выработке пластов). Технологические показатели разработки месторождения (динамика дебита, давления, обводненности и т.д.) с применением и без применения ОРЭ определяются обычными методами расчетов, используемых при проектировании разработки нефтяных и газовых месторождений.

Эффективность одновременной раздельной эксплуатация при решении задач первой группы характеризуется обеспечением оптимальных условий работы каждого пласта или осуществлением возможности контроля и регулирования разработки пластов. Количество скважин, в которых должно осуществляться ОРЭ, обосновывается в проекте, исходя из необходимости решения указанных задач.

Оценка эффективности метода, по количеству дополнительно добытой нефти после перевода скважин на одновременную раздельную эксплуатацию проводится лишь в частых случаях. В основном же при плановом и запроектированном технологической схемой разработки использовании метода дополнительная добыча должна учитываться при расчете показателей разработки.

При решении задач первой группы перевод скважин на ОРЭ может осуществляться как с самого начала ввода их в эксплуатацию, так и после определенного периода совместной эксплуатации пластов.

Время перевода скважин на ОРЭ определяется соответствующими расчетами при составлении проектов в зависимости от цели применения одновременной раздельной эксплуатации. В соответствии с режимом работы скважин в этот период в проекте должны быть даны рекомендации по выбору типа оборудования.

При совместной эксплуатации пластов в начальный период проводится систематический контроль за их разработкой. С помощью гидродинамических и промысловых исследований определяются характеристики пластов и скважин, и в результате соответствующих проверочных расчетов уточняется фонд скважин, время их перевода на ОРЭ и характеристики необходимого оборудования. 
Часть технологических задач первой группы по контролю и регулированию эксплуатации многопластового месторождения может решаться с помощью ОРЭ в процессе разработки. В этом случае технологическая и экономическая эффективность применения метода ОРЭ, а также время перевода скважин на ОРЭ оценивается по методам определения технологических показателей эффективности.

\section{Список литературы}

1. Будлов, С. Технологии ОРЭ и «интеллектуализации» скважин снижают риски и улучшают экономику добычи / С. Будлов // Инженерная практика. - 2010. - № 1. - 58-60 с.

2. Гарипов, О.М. Общие тенденции развития высокотехнологичного сервиса при разработке, установке и обслуживании многопакерных систем для одновременно-раздельной эксплуатации / О.М.Гарипов // Нефтяное хозяйство. - 2009. - № 9. - 58-61 c.

3. Ерастов, С.А. Технологии ОРЭ и ОРЗ для контроля, мониторинга и управления эксплуатацией многопластовых месторождений «РН-Юганскнефтегаз»: итоги 2010 года / С.А. Ерастов, Р.Н. Асмандияров, Э.Р. Назаргалин, П.И. Сливка // Инженерная практика. - 2011. - № 3. - 88-91 с.

4. Ивановский, В.Н. Одновременно-раздельная эксплуатация и «интеллектуализация» скважин: вчера, сегодня завтра / В.Н. Ивановский // Инженерная практика. - 2010. - № 1. - 5-15 с.

5. Кременецкий, М.И. Гидродинамические и промысловотехнологические исследования скважин / М.И. Кременецкий, А.И. Ипатов. М.: МАКС Пресс. -476 с.

6. Куликов, М.В. Технологические измерения и приборы / М.В. Куликов. - М: Недра, 1966. - 500с.

7. Никишов, В.И. Карты применимости компоновок для совместной разработки двух объектов / В.И. Никишов, Р.А. Хабибуллин, А.П. Сметанников, Д.А. Нижевич // Нефтяное хозяйство. - 2009. - № 11. $45-47 \mathrm{c}$. 